\title{
Academic Social Network Sites: Opportunities and Challenges
}

\author{
Mumtazimah Mohammad ${ }^{1}$, Yuzarimi M. Lazim ${ }^{2 *}$, Suharmili Rosle ${ }^{3}$ \\ ${ }^{I}$ Faculty of Informatics and Computing, University Sultan Zainal Abidin, Gong Badak Campus, 21300 Kuala Terenggan, Terengganu, \\ Malaysia. \\ ${ }^{2,3}$ Faculty of Informatics Science, University College Bestari, Putera Jaya, Bandar Permaisuri, 22100 Setiu, Terengganu, Malaysia \\ *Corresponding author E-mail: yuzarimi@ucbestari.edu.my
}

\begin{abstract}
Academic Social Networking Sites (ASNs) have become one of the most important platforms in modern information and education industries. It will definitely become an essential mechanism to communicate, connect and collaborate among the scholarly community. In this paper, we provide a comprehensive investigation of ASNs such as Academia, ResearchGate, Mendeley and Zotero, and identify the features of ASNs. We also discuss the opportunities for ASNs and provide the challenges. Challenges related to ASNs are: collecting relevant data and identifying data quality, finding evaluation metrics and also developing efficient algorithms. Disciplinary differences in domain area and academic position become the opportunities why academicians use ASNs.
\end{abstract}

Keywords: Academic Social Network Sites,ASNs, Academia.edu, ResearchGate, Research Network

\section{Introduction}

A web-based social networking service is one of the possible ways to connect people who share interests and activities across political, economic, and geographic borders [1]. [2] stated that, social networking sites share a variety of technical features that allow individuals to construct a public/semi-public profile, articulate a list of other users that they share a connection with, and view their list of connections within the system [3-4]. Social networking services can be divided into three categories which are [5]:

- $\quad$ Connect with existing friends (e.g., Facebook);

- $\quad$ Communicate with non-social interpersonal community (e.g., LinkedIn); and

- Help users to find specific information or resources (e.g., Google Scholar).

Academic social networking sites or ASNs are more specific to academicians in sharing their activities, specializations, publications and assessing other impacts of scholarly contribution. Thewall \& Kousha [6] stated that academic network services are online services that focus on supporting online research-oriented activities as well as building social networks for scholars and researchers. According to [7], one of the factors student using social networking sites is to do a sort of collaborative study, academic or research work.

A variety of academic social networking platforms, including ResearchGate, Academia.edu, Google Scholar, Mendeley and Zotero have gained popularity over the past decade [8].

The objectives of this paper are to provide a comprehensive review of four popular ASNs and their features. The statistical comparison between the current ASNs is discussed. In addition, the opportunities and research challenges are discussed, focusing on research issues such as determining metrics, gathering relevant data and developing efficient algorithms.

\section{Related Work}

Nowadays, people are using these ASN websites for many purposes. This is due to the high operating capability of these ASN websites to provide an online community service and groupcentered via sharing information, interaction with others, and looking for expertise in their domain of interest. Below are the details of the functionality of some ASNs and their relative benefits for professional development.

\subsection{ResearchGate}

ResearchGate (RG) is an ASN that allows researchers to upload their research papers, join discussions and follow other researcher activities. The main purpose of RG is to communicate with scientists all around the world to share their interest. It provides a free signing up account for users to create an online profile, share their idea, and search lists of conferences.

Besides that, this site can be very obliging in locating conference materials such as articles, posters and slide decks that are not archived in other ASNs. Other than that, RG users can receive scores on their publications including the number of times their papers have been viewed and cited by other users on RG. RG provides a platform for communication purposes that distinguishes it from other ASNs. Through RG, researchers can:

- Ask questions and respond to all users regarding their subject matter.

- Obtain notifications whenever new work is uploaded.

- Directly message to request feedback through RG's messaging system.

- Request to share full versions of articles.

- Allows generation of project logs on their current projects.

- Request to submit papers as special issues in journal body. 


\subsection{Academia.Edu}

Academia.edu is an ASN which provides academic papers that can be shared among researchers. Through Academia, users can create their profiles and upload a list of their research outputs. This user account includes statistics on views and social interactions such as followers and following.

To achieve their goal, Academia.edu is developed as a medium to provide academicians to share their research or article with over a billion researchers around the world. Users can sign up for free and it is easy to create a profile. A major advantage of Academia.edu is researchers can upload various documents and follow a various range of topic interest.

Users on Academia.edu can import contacts from other social network accounts to find members which have Academia.edu profiles. Nevertheless, in order to avoid receiving a takedown notice from the editor before using these services, it is required for users to follow and check the policy guidelines for each journal before sharing an article [9].

\subsection{Mendeley}

Mendeley.com is a free reference tool and ASN that helps academicians to organize their paper, cooperate with others virtually, and discover the latest research around the world. Mendeley helps users to upload and share files that encourages collaboration with other groups by sharing papers, following updates, making comments and tracking progress within the groups. Another function in Mendeley is users are allowed to search and upload papers to their profile's library and directly leave a comment on their colleagues' papers. Mendeley is not only free to sign up, but users are able to download it to the personal desktop.

\subsection{Zotero}

Other than RG, Academia.edu and Mendeley, Zotero helps users to cite, collect, share and organize their study sources easily. It is a well-known and useful website with significant communities or groups. Zotero hosts groups which allow users to connect, work together with other experts and discover other works from various fields so that the users can be kept updated on the issue and connected with surrounding people. It is free to sign up and downloadable to a computer. [10] listed the common features these ASNs have as follows:

- File repository;

- Free sign up;

- Discussion boards;

- Email/Message;

- Alt Metrics;

- Citation count;

- Group space;

- Public/semi-public profile;

- Reference management;

- Network visibility;

- Collaborative document processing;

- Upload publications; and

- $\quad$ Link to social media sites.

\subsection{Opportunities and Comparison of Current Asns}

Academia.edu was found to be the most popular ASN among other networks with more than 58 million users registered. Academia.edu sites was conquered by Indonesia (21.9\%), while United States was the second highest country that used Academia.edu, followed by India (6.5\%), China (4.9\%) and Japan (3.2\%). China dominated the highest usage for Mendeley.com, which was 32.5\%. Based on statistics, Asian countries such as China, Indonesia, Japan and India were the highest users of ASNs.

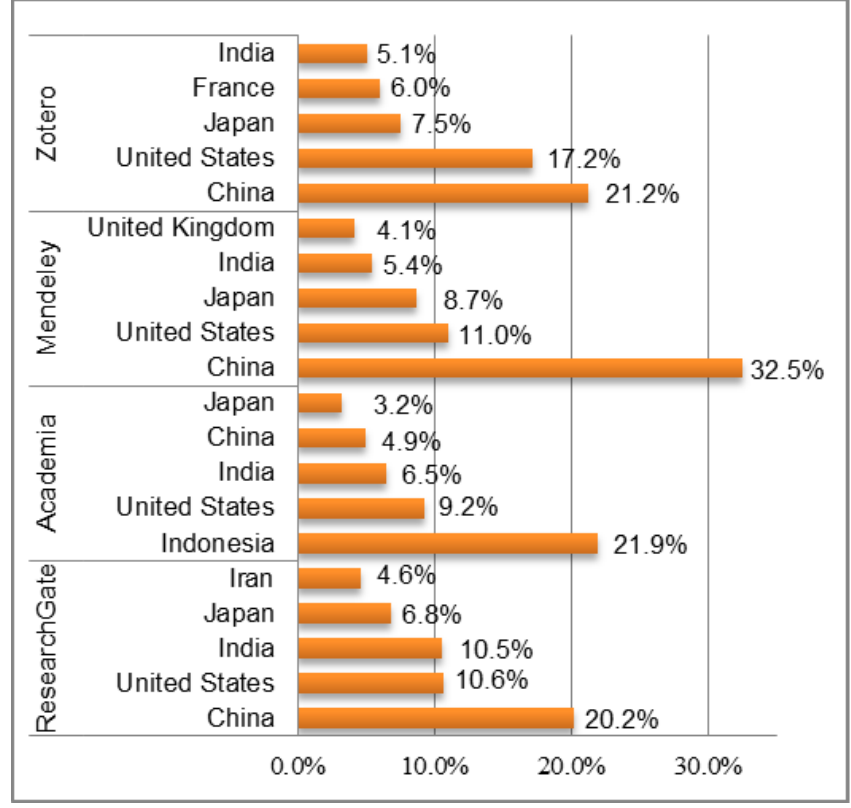

Fig. 1: Audience Geography

Table I presents statistical information on the most popular ASNs from year 2006 until 2008. Alexa website lists the oldest as Zotero.org, which was created in October 2006, followed by ResearchGate.net, Mendeley.com and Academia.edu which were launched in 2008 .

Table 1: Statistical Information of ASNs

\begin{tabular}{|c|c|c|c|c|c|}
\hline ASNs & $\begin{array}{c}\text { Traffic } \\
\text { Rank }\end{array}$ & $\begin{array}{c}\text { Number } \\
\text { of } \\
\text { Users }\end{array}$ & $\begin{array}{c}\text { Page } \\
\text { Views } \\
\text { per } \\
\text { User }\end{array}$ & $\begin{array}{c}\text { Average } \\
\text { Time } \\
\text { on Site }\end{array}$ & $\begin{array}{c}\text { Creation } \\
\text { Year }\end{array}$ \\
\hline Academia.edu & 591 & $\begin{array}{c}>58 \\
\text { million }\end{array}$ & 1.71 & $2: 25$ & $\begin{array}{c}\text { Sept, } \\
2008\end{array}$ \\
\hline $\begin{array}{c}\text { Mendeley.com } \\
\text { lion }\end{array}$ & 4,930 & $\begin{array}{c}>6 \text { mil- } \\
\text { lion }\end{array}$ & 2.77 & $4: 27$ & $\begin{array}{c}\text { Aug, } \\
2008\end{array}$ \\
\hline $\begin{array}{c}\text { ResearchGate. } \\
\text { net }\end{array}$ & 227 & $\begin{array}{c}>11 \\
\text { million }\end{array}$ & 2.12 & $2: 36$ & $\begin{array}{c}\text { May, } \\
2008\end{array}$ \\
\hline $\begin{array}{c}\text { Zotero.org } \\
\text { lion }\end{array}$ & 13,987 & $\begin{array}{c}>2 \text { mil- } \\
\text { Statisting }\end{array}$ & 3.21 & $4: 04$ & $\begin{array}{c}\text { Oct, } \\
2006\end{array}$ \\
\hline
\end{tabular}

Statistics for average time on site shows that members of Mendeley and Zotero spend more time surfing these websites compared to other ASNs. These two websites also have the highest rate of page views per user and average time on site with 2.77 and 4:27 for Mendeley, and 3.21 and 4:04 for Zotero.org. ResearchGate.net has the best traffic rank with 227, followed by Academia.edu (591), Mendeley.com $(4,930)$ and Zotero.org $(13,987)$. From this viewpoint, Zotero is the oldest and has the lowest traffic rank $(13,987)$ compared with Mendeley which has an attractive interface, 2GB free storage space and lots of resources that can be accessed. Therefore, these differences in traffic rank are really important when targeting specific users. Figure 2 to Figure 5 present Alexa's traffic ranks based on the traffic data provided by users in Alexa's global data panel for a period of three months starting from September 2017 to January 2018. 


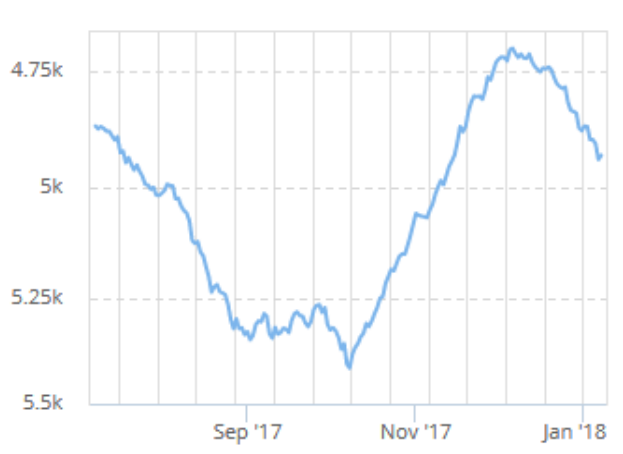

Fig. 2: Mendeley.com

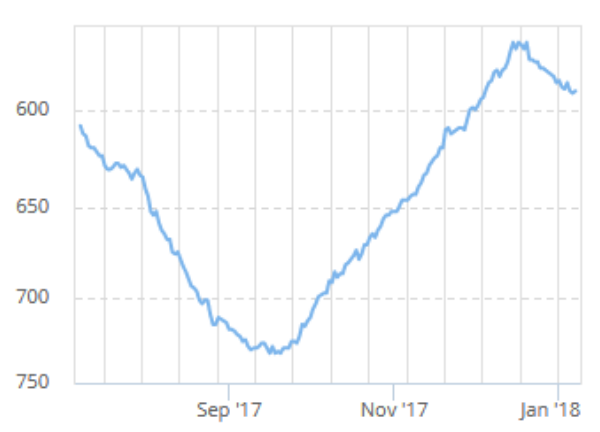

Fig. 3: Academia.edu

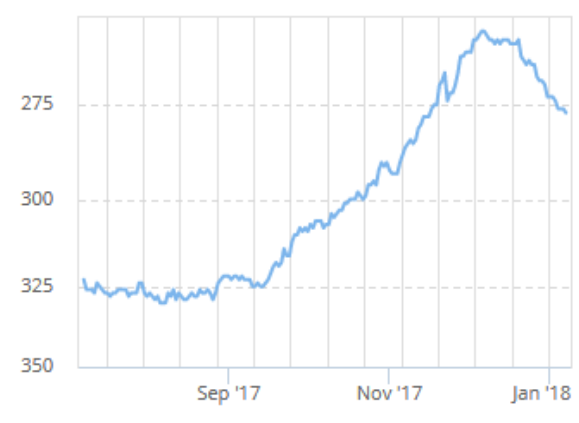

Fig. 4: ResearchGate.net

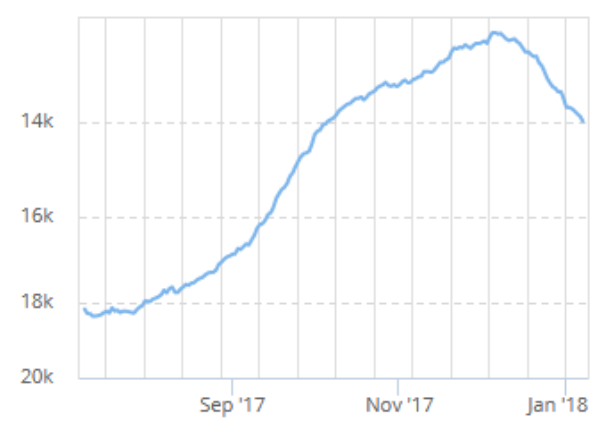

Fig. 5: Zotero.org

Table II shows different ways of ASNs that supported scholarly works and their findings in various focused areas.

Table 2: Previous Studies of ASNs

\begin{tabular}{|l|l|}
\hline $\begin{array}{l}\text { Author(s) } \\
\text { /Year }\end{array}$ & Findings \\
\hline $\begin{array}{l}\text { Williams and } \\
\text { Woodacre[9] }\end{array}$ & $\begin{array}{l}\text { Discovered the characteristics and utilities of ASNs and } \\
\text { compared the unique attributes of ASNs. }\end{array}$ \\
\hline Ortega[11] & Studied the differences based on disciplines in the use of \\
\hline
\end{tabular}

\begin{tabular}{|c|c|}
\hline & $\begin{array}{l}\text { several ASNs. The study found that Academia.edu was } \\
\text { widely used by humanists and social scientists, whereas } \\
\text { ResearchGate was popular among biologists. }\end{array}$ \\
\hline $\begin{array}{l}\text { Mikki } \\
\text { al.[12] }\end{array}$ & $\begin{array}{l}\text { Compared the profiles of researchers from the Universi- } \\
\text { ty of Bergen on five sites and found that } 37 \text { per cent of } \\
\text { the researchers have registered in at least one ASNs. } \\
\text { The highest prevalence was observed in the Faculty of } \\
\text { Psychology and Faculty of Social Sciences ( }>40 \text { per } \\
\text { cent). Women were unrepresented; presence of profes- } \\
\text { sors and doctorate students were found to be the highest } \\
\text { users of ASNs. }\end{array}$ \\
\hline Megwalu[13] & $\begin{array}{l}\text { Revealed that linguists and sociologists were more } \\
\text { proficient in using Academia.edu and other ASNs com- } \\
\text { pared to physicists. The study found that differences in } \\
\text { use across disciplines were influenced by variations in } \\
\text { the social and cultural practices of the disciplines. }\end{array}$ \\
\hline $\begin{array}{ll}\text { Vasquez } & \text { et } \\
\text { al.[14] } & \end{array}$ & $\begin{array}{l}\text { Reported that ASNs offered a combination of tools to } \\
\text { support research activities, collaboration and network- } \\
\text { ing, but maintaining multiple profiles on various sites } \\
\text { could be a time-consuming process. }\end{array}$ \\
\hline $\begin{array}{l}\text { Kraker and } \\
\text { Lex[15] }\end{array}$ & $\begin{array}{l}\text { Criticizes the ResearchGate score in assessment of } \\
\text { academic studies. The authors found major limitations } \\
\text { for the score as it was non-transparent, irreproducible, } \\
\text { incorporates journal impact factor, and changes in the } \\
\text { score cannot be reconstructed. }\end{array}$ \\
\hline Jeng et al.[16] & $\begin{array}{l}\text { Reported that females had significantly stronger motiva- } \\
\text { tions for joining a group in Mendeley.com }\end{array}$ \\
\hline $\begin{array}{l}\text { Salahshour et } \\
\text { al.[17] }\end{array}$ & $\begin{array}{l}\text { Studied the impact of demographic factors such as gen- } \\
\text { der, age, academic position and academic researchers' } \\
\text { experience on ASNs. The authors found that age and } \\
\text { experience do not affect collaboration technology in } \\
\text { ASNs. Nevertheless, the study revealed that academic } \\
\text { position had an effect on ASNs use. }\end{array}$ \\
\hline
\end{tabular}

Generally, it can be concluded that researchers from social areas such as linguists, sociologists and humanities are much more active using Academia.edu, while ResearchGate attracts the attention of researchers from biological fields (Table II). Thus, this indicated that researchers of social studies are active users of ASN sites because they have high rates of social connection and usage compared to other research areas.

Findings from previous studies revealed that academic position has an effect on ASNs use. Senior academics such as professors, lecturers and post graduate students are the highest users of ASNs compared to other academic positions. This is due to lecturers and professors requiring a connection with the other ASNs in the invention of their studies. However, research assistants and research fellows only require a few literature reviews in their research because they are supported by a few research work.

\section{Challenges for ASNs}

Social networking is a collection of vast data sets with a great variety of types from social media, such as Twitter, Facebook, and Linkedln. Nowadays, the explosion of data in terms of value, volume, veracity, velocity, and variety, or known as $5 \mathrm{~V}$, powered by exciting and magnificent advances in web techniques and information technologies have become the center of general attention. Since the early 2000s, the impulsive growth in the use of social media has provided rich sources of data for researchers. This phenomenon has created new challenges to academicians in order to develop intellectual and ethical process and approaches in many research discipline areas. The researchers have to face a number of difficulties in relation to social media such as collection of relevant data, data quality, determining metric, and develop efficient algorithms. The challenges in each area are itemized as follows:

\subsection{Collection of Relevant Data}

Additional invasion of privacy may arise, due to the vulnerability of information on social connection [18]. The problem to obtain the data is more attentive because users keep their privacy. There were no approach methods to collect the scientific data. Normally, data collection is done by interviews or distributing questionnaires to small-scale group studies with volunteers [18]. Because of that 
issue, collection of appropriate data was one of the major barriers to achieve an ASN analysis.

\subsection{Data Quality}

Open data allows an organization to provide information and data to be accessible to the public. The quality of data disclosure is the advancement of service quality to the community. The more data that can be accessed by the public, the more that data benefits. However, transparency and quality improvement are common goals to get quality data. It requires the difficulty of computation in analysing social networks because of zillions of nodes, and consolidation of multiple data sources.

\subsection{Determining Evaluation Metrics}

The data set used in the research was obtained from various sources and methods. The ASN data set process analysis must be uniform in all aspects. To assess ASN metrics, a set of effective evaluation metrics is needed to provide assistance in designing new models, as well as to explain the complex phenomena in social networks. However, it is an issue to determine a set of effective evaluation metrics in real social networks, because of the complex and universal scale in the topology of social networks.

\subsection{Develop Efficient Algorithms}

Considering the rapid evolution of Web 2.0, the process of raw data collection from social networks such as Twitter and offline sources is much easier. However, the advance growth of social network must be developed for efficient algorithms to handle these issues. The wide usage of social media has created a large amount of data collaboratively and provides new opportunities to obtain any relevant data. The development of cloud computing also accelerates the emergence of ASN data. ASN data can effectively be managed with the distributed storage technology based on cloud computing. The integrity of cloud computing can improve the efficiency of analysis on ASN data using techniques such as data mining and parallel computing.

With extensive investigation on the analysis and modelling of ASN, a few methods and technologies are being utilized in this domain, such as data mining, machine learning, neural networks and parallel processing. These methods and technologies are given a wide scope as a way to study ASN.

\section{Conclusion}

In this article, a study of academic social network sites from two different perspectives: properties of ASNs and statistical comparisons of ASNs were reviewed. This study also discusses the opportunities for ASNs, and provides the challenges for ASNs in social networking. This discussion should be considered as a guide for academicians or researchers to analyse the current increasing data from various ASNs and provide motivation for further research on social network analysis, and also new opportunities in the area of new emerging technologies. Future research could explore the comprehensive investigation of the architecture of ASNs based on mining social network.

\section{Acknowledgement}

This work was supported by the Fundamental Research Grant Scheme (FRGS/1/2015/ICT02/UNISZA/02/1) by Malaysia Ministry of Higher Education and the Center of Research and Innovation Management of Universiti Sultan Zainal Abidin, Terengganu, Malaysia.

\section{References}

[1] Solomon G, Schrum L. Web 2.0 How-to for Educators, 2nd Edition. 2014: International Society for Technology in Education.

[2] Boyd D. Why Youth (Heart) Social Network Sites: The Role of Networked Publics in Teenage Social Life, in Youth, Identity, and Digital Media Volume D. Buckingham, Editor, (2007), MIT Press: Cambridge, MA.

[3] Boyd D, Ellison NB, Social Network Sites: Definition, History, and Scholarship, Journal of Computer-Mediated Communication, 13(1), (2007), 11 .

[4] Goyal S, Facebook, Twitter, Google +: Social Networking, International Journal of Social Networking and Virtual Communities, 1(1), (2012),16-18.

[5] Thelwall MA, Social Network Sites: Users and Uses, Advances in Computers, 76(4),(2014) 19-73.

[6] Thelwall MA, Kousha K, Academia. Edu: Social Network or Academic Network? Journal of the Association for Information Science and Technology, 65(4),(2014), 721-731.

[7] Helou AM, Zor Zairah AR, Oye ND, Students' Perceptions on Social Networking Sites Influence on Academic Performance, International Journal of Social Networking and Virtual Communities, 1(1), (2102) 7-15.

[8] Ovadia S, Researchgate And Academia.Edu: Academic Social Networks, Behavioral \& Social Sciences Librarian, 33(3),(2014), 165-169.

[9] Williams AE, Woodacre MA, The Possibilities and Perils of Academic Social Networking Sites, Online Information Review, 40(2), (2016), 282-294.

[10] Espinoza Vasquez FK, Caicedo Bastidas CE, Academic Social Networking Sites: A Comparative Analysis of Their Services and Tools, iConference 2015, Newport Beach, CA, USA,(2015), IDEALS.

[11] Ortega JL, Disciplinary Differences in The Use of Academic Social Networking Sites, Online Information Review, 39(4), (2015), 520536.

[12] Mikki S, et al, Digital Presence Of Norwegian Scholars On Academic Network Sites - Where And Who Are They? PloS one, 10(11),(2015), e0142709.

[13] Megwalu A, Academic Social Networking: A Case Study On Users' Information Behavio, in Current Issues in Libraries, Information Science and Related Fields. Emerald Group Publishing, London, 185-214.

[14] Vasquez E, Karely F, Bastidas CES, Academic Social Networking Sites: A Comparative Analysis of Their Services and Tools, iConference Proceedings. Illinois, (2015)

[15] Kraker P, Lex E, A Critical Look At The Researchgate Score As A Measure of Scientific Reputation, Web Science Conference, Oxford, (2015).

[16] Jeng W, He D, Jiang J, User Participation In An Academic Social Networking Service: A Survey of Open Group Users on Mendeley, Journal of the Association for Information Science and Technology, 66(5), (2015), 890-904.

[17] Salahshour M, Dahlan HM, Iahad NA, A Case of Academic Social Networking Sites Usage in Malaysia: Drivers, Benefits, and Barriers, International Journal of Information Technologies and Systems Approach (IJITSA), 9(2),(2016), 88-99.

[18] Bonchi F, et al, Social Network Analysis and Mining for Business Applications, ACM TrASNsactions on Intelligent Systems and Technology (TIST), 2(3),(2011), 22. 